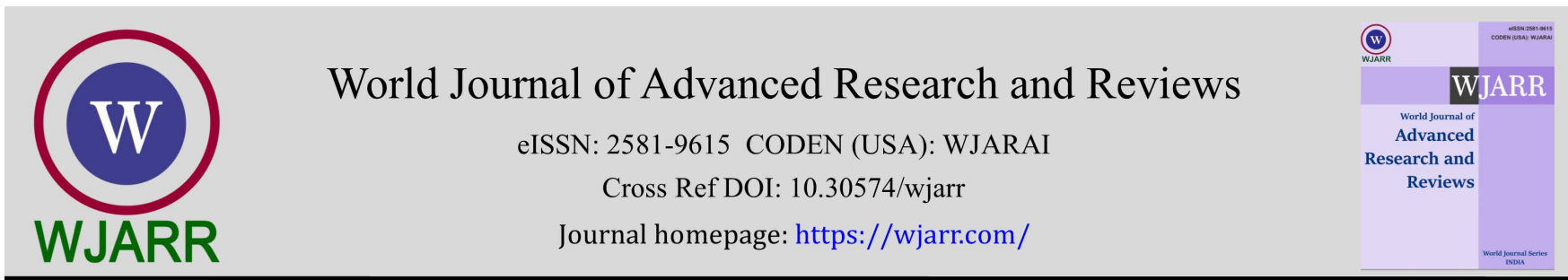

(RESEARCH ARTiClE)

Check for updates

\title{
Clinicopathologic profile of sinonasal diseases in a tertiary hospital in Port Harcourt
}

\author{
Matilda Uju Ibekwe * and Edirirn Nosa Oghenekaro \\ Ear Nose And Throat Surgery Department, University of Port Harcourt Teaching Hospital, Port Harcourt, Rivers State, \\ Nigeria.
}

World Journal of Advanced Research and Reviews, 2021, 10(01), 012-018

Publication history: Received on 23 February 2021; revised on 27 March 2021; accepted on 30 March 2021

Article DOI: https://doi.org/10.30574/wjarr.2021.10.1.0126

\begin{abstract}
Background: In a typical ear nose and throat clinic, disease conditions involving the nose and paranasal sinuses are not uncommon. The aim of this study is to determine the clinicopathologic profile of these diseases as it occurs in university of Port Harcourt teaching hospital.

Methodology: A retrospective descriptive analysis of all patients with diagnosis of sinonasal disease that presented in the ear nose and throat surgery department of university of Port Harcourt teaching hospital within the period of 5years (from 2016 - 2020). Data retrieved were biodata, clinical features, diagnosis and treatment, these were all collated and analysed. Patients without complete records were excluded. The patients recruited had clinical diagnosis which was aided by radiological investigations and confirmed by histology.

Result: A total of 68 patients were studied within the 5 year period. There were 35 males and 33 females. The mean age was 33.96+/_17.9 years. The age groups 11-20 and 41-50 were more affected. Rhinosinusitis was the commonest condition seen while inflammatory polyp was the commonest histologic diagnosis. Polypectomy with bilateral antrostomy was the commonly done surgery in $26.4 \%$ age.

Conclusion: Disease of the nose and paranasal sinuses are commonly seen in ENT practice and rhinosinusitis is the commonest entity encountered with inflammatory polyp as the commonest histopathologic finding. Squamous cell carcinoma was the commonest malignant lesion seen occurring more in males. Age distribution of the diseases was statistically significant.
\end{abstract}

Keywords: Sinonasal disease; Histology; Rhinosinusitis; Antrostomy; Polypectomy

\section{Introduction}

Owing to the congruity of the nose and paranasal sinuses, disease conditions affecting one area can extend to the other. This can be due to the fact that the mucosal lining of the nasal cavities are continuous with that of the paranasal sinuses [1]. The nose majorly form the shape of the face and therefore aesthetic functions, pathologies affecting it tend to be immediately obvious [2].

The conditions can primarily arise from the nose and paranasal sinuses but can also be as a result of extensions from surrounding structures especially the orbit, the dental apparatus or the cranium and its contents $[3,4,5]$. The disease conditions can be inflammatory, infective or neoplastic. Rhinosinusitis an inflammatory and infective condition of the nose and paranasal sinus has been documented to be a commonly occurring condition [6]. While some others like nasal and antrochoanal polyps, foreign bodies in the nose and some malignant lesions have all been documented [7,8]. Benign

*Corresponding author: Matilda Uju Ibekwe; Phone: 07039120091; Email: ibekwe_uju@yahoo.com

Ear Nose And Throat Surgery Department, University of Port Harcourt Teaching Hospital, Port Harcourt, Rivers State, Nigeria. 
neoplasia of the nose and paranasal sinuses can often be encountered in a typical ORL clinic while the malignant ones are not as common. They constitute $<1 \%$ of all cancers but $3 \%$ of the head and neck cancers [9]. Nasal polyps as a disease entity have been known as far back as in ancient Egypt [10]. it is rare in children [11] and seen more in ages $>20 y e a r s$ [12].

Some of these diseases are known to have high burden of morbidity and mortality with clinical presentations depending on the site and extension of the disease [13]. The commonly documented features include nasal obstruction, discharge, facial swelling, epistaxis, nasal mass, headaches $[14,15,13]$. it is also known that these patients tend to present very late to the hospital and hence are seen as very advanced disease [16,17]. Eye/Ocular features such as proptosis, orodental symptoms are all features of advanced disease [6].The treatment in such advanced cases may require team collaboration with other specialists such as neurosurgeons, ophthalmologists and maxillofacial surgeons [18]. This study therefore is to determine the clinicopathologic profile of these diseases as seen in the ENT surg department of UPTH.

\section{Methodology}

A retrospective descriptive analysis of all patients with diagnosis of sinonasal disease that presented in the ear nose and throat surgery department of university of Port Harcourt teaching hospital within the period of 5years (from 2016 2020). Data retrieved were biodata, clinical features, diagnosis and treatment, these were all collated and analysed. Patients without complete records were excluded. The patients recruited had clinical diagnosis which was aided by radiological investigations and confirmed by histology.

Descriptive statistics (frequency and percentage) was used to present distribution of the data. A cross-tabulation of diagnoses by demographic data was done with the Chi-square statistic. The analyses were with the SPSS v25 software at a $95 \%$ confidence interval and a p-value less than 0.05 was considered significant.

\section{Results}

The study comprised of 68 patients with age range from 3years to 70years and a mean age of 33.96+/- 17.9years. There were 35 males and 33 females with male: female ratio of 1:1.06. The age group 11-20 years and 41-50 comprised the majority of the population studied. (Table1).

Table 1 Demographic Distribution of participants.

\begin{tabular}{|l|l|l|}
\hline Demographics & Frequency (n = 68) & Percentage (\%) \\
\hline Gender & \multicolumn{1}{|l|}{} \\
\hline Male & 35 & 51.5 \\
\hline Female & 33 & 48.5 \\
\hline Age groups (years) & \multicolumn{1}{|l|}{} \\
\hline $1-10$ & 6 & 8.8 \\
\hline $11-20$ & 14 & 20.6 \\
\hline $21-30$ & 10 & 14.7 \\
\hline $31-40$ & 13 & 19.1 \\
\hline $41-50$ & 14 & 20.6 \\
\hline $51-60$ & 5 & 7.4 \\
\hline $61-70$ & 6 & 8.8 \\
\hline Mean Age & $33.96 \pm 17.9$ & \\
\hline
\end{tabular}

Majority of the patients commonly had nasal blockage and rhinorrhea as main complaints; $52.3 \%$ and $19.2 \%$ respectively and epistaxis in $10.1 \%$. (Table 2) The commonest sinonasal disease in the study was rhinosinusitis in $32.4 \%$ followed by $26.5 \%$. The nasal and nasopharyngeal tumor were $3^{\text {rd }}$ and $4^{\text {th }}$ commonly recorded and fungal sinusitis was 
seen in 4.4\%. (Table 3) Different surgeries were performed within the period of study. The commonest was nasal clearance with either right or left intranasal antrostomy (45.5\%). Polypectomy with bilateral intranasal antrostomy was done in $26.4 \%$ and was the second commonly performed surgery. However nasal clearance and BINA was carried out in $11.8 \%$ (table 4). Histologic distribution showed inflammatory polyp as the commonest in $54.4 \%$ followed by squamous carcinoma in $17.65 \%$ with adenocarcinoma and fungal sinusitis in $8.82 \%$ respectively.(Table 5) squamous cell carcinoma was seen more in the males; $22.86 \%$ while inflammatory polyps was seen more in females; $63.64 \%$ however, the distribution of sinonasal diseases according to gender was not significant statistically; $\mathrm{p}=0.211$.(table 6) The age distribution showed adenocarcinoma was commoner in the ages 31-70 years; inflammatory polyp was seen more in ages 11-50years. Squamous carcinoma was seen more among the older age groups. The distribution was significant statistically. $\mathrm{P}=0.032$ (Table 7).

Table 2 Distribution of Symptoms

\begin{tabular}{|c|c|c|}
\hline Symptoms & Frequency (n) & Percent (\%) \\
\hline Nasal blockage & 57 & 52.3 \\
\hline Rhinorrhoea & 21 & 19.2 \\
\hline Epistaxis & 11 & 10.1 \\
\hline Facial asymmetry & 7 & 6.4 \\
\hline Nasal mass & 4 & 3.6 \\
\hline Proptosis & 2 & 1.8 \\
\hline Rhinolalia clausa & 2 & 1.8 \\
\hline Sneezing & 2 & 1.8 \\
\hline Discharge from side of eyebrow & 1 & 0.9 \\
\hline Neck swelling & 1 & 0.9 \\
\hline Ulcer in the nose & 1 & 0.9 \\
\hline Total & 109 & 100.0 \\
\hline \multicolumn{2}{|c}{ Multiple responses apply } \\
\hline
\end{tabular}

Table 3 Distribution of Diagnoses

\begin{tabular}{|l|l|l|}
\hline Diagnosis & Frequency & Percent \\
\hline Rhinosinusitis & 22 & 32.4 \\
\hline Sinonasal tumor & 18 & 26.5 \\
\hline Nasopharyngeal tumor & 9 & 13.2 \\
\hline Nasal mass & 8 & 11.8 \\
\hline Fb in the nose & 3 & 4.4 \\
\hline Fungal sinusitis & 3 & 4.4 \\
\hline Nasal synechae & 2 & 2.9 \\
\hline Ethmoidal mucocele & 1 & 1.5 \\
\hline Frontoethmoidal fistula & 1 & 1.5 \\
\hline Inverted papilloma & 1 & 1.5 \\
\hline Total & 68 & 100 \\
\hline
\end{tabular}


Table 4 Distribution of Surgery

\begin{tabular}{|l|l|l|}
\hline Surgery & Frequency & Percent \\
\hline Nasal Clearance +Rt/Lt Ina & 31 & 45.5 \\
\hline Polypectomy +Bina & 18 & 26.4 \\
\hline Nasal Clearance+Bina & 8 & 11.8 \\
\hline Caldwel-Luc & 4 & 5.9 \\
\hline Fb Removal & 3 & 4.4 \\
\hline Adhesiolysis +Stenting & 2 & 2.9 \\
\hline External Frontoethmoidectomy & 1 & 1.5 \\
\hline External Ethmoidectomy & 1 & 1.5 \\
\hline Total & 68 & 100 \\
\hline
\end{tabular}

Table 5 Distribution of Histology

\begin{tabular}{|l|l|l|}
\hline Distribution of Surgery & Frequency (n) & Percent (\%) \\
\hline Inflammatory polyps & 37 & 54.41 \\
\hline Squamous cell carcinoma & 12 & 17.65 \\
\hline Adenocarcinoma & 6 & 8.82 \\
\hline Invasive fungal sinusitis & 6 & 8.82 \\
\hline Fungal sinusitis & 2 & 2.94 \\
\hline Lymphoma & 2 & 2.94 \\
\hline Papilloma & 2 & 2.94 \\
\hline Mucoepidermoid carcinoma & 1 & 1.47 \\
\hline Total & 68 & 100 \\
\hline
\end{tabular}

Table 6 Distribution of Histology by Gender.

\begin{tabular}{|c|c|c|c|}
\hline Histology & Male & Female & Chi-square (p-value) \\
\hline Squamous cell carcinoma & $8(22.86)$ & $4(12.12)$ & \multirow{8}{*}{$9.62(0.211)$} \\
\hline Papilloma & $2(5.71)$ & $0(0)$ & \\
\hline Mucoepiemoid carcinoma & $0(0)$ & $1(3.03)$ & \\
\hline Lymphoma & $2(5.71)$ & $0(0)$ & \\
\hline Invasive fungal sinusitis & $3(8.57)$ & $3(9.09)$ & \\
\hline Inflammatory polyps & $16(45.71)$ & $21(63.64)$ & \\
\hline Fungal sinusitis & $0(0)$ & $2(6.06)$ & \\
\hline Adenocarcinoma & $4(11.43)$ & $2(6.06)$ & \\
\hline
\end{tabular}


Table 7 Distribution of Histology by Age Group.

\begin{tabular}{|c|c|c|c|c|c|c|c|c|}
\hline \multirow[b]{2}{*}{ Histology } & \multicolumn{7}{|c|}{ Age-Group (years) } & \multirow{2}{*}{$\begin{array}{l}\text { Chi- } \\
\text { square (p- } \\
\text { value) }\end{array}$} \\
\hline & $\begin{array}{l}1-10 \\
n,(\%)\end{array}$ & $\begin{array}{l}11-20 \\
n,(\%)\end{array}$ & $\begin{array}{l}21-30 \\
\mathrm{n},(\%)\end{array}$ & $\begin{array}{l}31-40 \\
\mathrm{n},(\%)\end{array}$ & $\begin{array}{l}41-50 \\
\mathrm{n},(\%)\end{array}$ & $\begin{array}{l}51-60 \\
\mathrm{n},(\%)\end{array}$ & $\begin{array}{l}61-70 \\
n,(\%)\end{array}$ & \\
\hline Adenocarcinoma & $0(0.0)$ & $0(0.0)$ & $0(0.0)$ & $1(7.69)$ & $1(7.14)$ & $1(20)$ & $3(50)$ & \multirow{9}{*}{$\begin{array}{l}60.54 \\
(0.032)^{*}\end{array}$} \\
\hline Fungal sinusitis & $0(0.0)$ & $1(7.14)$ & $0(0.0)$ & $0(0.0)$ & $1(7.14)$ & $0(0.0)$ & $0(0.0)$ & \\
\hline $\begin{array}{l}\text { Inflammatory } \\
\text { polyps }\end{array}$ & $2(33.33)$ & $8(57.14)$ & $9(90)$ & $7(53.85)$ & $7(50)$ & $3(60)$ & $1(16.67)$ & \\
\hline $\begin{array}{l}\text { Invasive fungal } \\
\text { sinusitis }\end{array}$ & $3(50)$ & $0(0.0)$ & $1(10)$ & $1(7.69)$ & $1(7.14)$ & $0(0.0)$ & $0(0.0)$ & \\
\hline Lymphomas & $1(16.67)$ & $1(7.14)$ & $0(0.0)$ & $0(0.0)$ & $0(0.0)$ & $0(0.0)$ & $0(0.0)$ & \\
\hline $\begin{array}{l}\text { Mucoepidermoid } \\
\text { carcinoma }\end{array}$ & $0(0.0)$ & $1(7.14)$ & $0(0.0)$ & $0(0.0)$ & $0(0.0)$ & $0(0.0)$ & $0(0.0)$ & \\
\hline Papilloma & $0(0.0)$ & $2(14.29)$ & $0(0.0)$ & $0(0.0)$ & $0(0.0)$ & $0(0.0)$ & $0(0.0)$ & \\
\hline $\begin{array}{l}\text { Squamous cell } \\
\text { carcinoma }\end{array}$ & $0(0.0)$ & $1(7.14)$ & $0(0.0)$ & $4(30.77)$ & $4(28.57)$ & $1(20)$ & $2(33.33)$ & \\
\hline Total & $0(0.0)$ & $0(0.0)$ & $0(0.0)$ & $1(7.69)$ & $1(7.14)$ & $1(20)$ & $3(50)$ & \\
\hline
\end{tabular}

\section{Discussion}

In the present study, the age range was 3years to 70years and it was found that there was almost equal representation of both males and females contrary to other researchers that found males more than females [8] while a study in Kaduna Nigeria found females more affected than males, however the study was on sinonasal masses only [7]. There appear to be a double peak in the age group affectation. The first peak is in the age 11-20 years with incidence of $20.6 \%$ and after age 30years, the incidence increased again across the ages peaking at age $41-50$ years before tapering down to $7.4 \%$ differing from other similar works that have older age groups being more affected $[7,8]$.

In this study the commonest disease conditions found were rhinosinusitis followed by sinonasal and nasopharyngeal tumors similar to other findings [6,7]. The commonly seen clinical features of sinonasal diseases in the present study were nasal blockage, rhinorrhea and epistaxis as was also documented by other works [13]. In addition those with advanced disease extending to congruent structures such as the eye/orbit had features such proptosis and facial asymmetry $[14,18,19]$ Majority of the tumours/ masses were seen in advanced stages as already documented by others and some of the factors deduced for this included; self- medication, quackery, poverty and fact that the sinonasal region is an area that appears hidden $[13,16,17]$.

Most of the patients had surgical management and nasal clearance with intranasal antrostomy was commonly done.it was usually the preliminary surgical procedure often as a form of biopsy prior to definitive surgery. Polypectomy with bilateral antrostomy was the second commonest surgery and this was similar to the findings in some earlier works $[6,8]$.

Histological diagnosis was carried out in all the patients with masses including the rhinosinusitis complicated with polyps. Inflammatory polyps were the commonest histology returned while squamous cell carcinoma was second but the commonest malignant lesion recorded in agreement with other works [19]. When the histologic diagnosis was correlated with se, it was found that squamous carcinoma was commoner in males while inflammatory polyps were commoner in females. However, this difference was not found to be significant statistically. The age distribution however showed inflammatory polyp to be more among the ages 11-50 years while the malignant lesions such as adenocarcinoma was found more in ages 31-70 years more commonly. The age distribution of the histologic forms of these diseases was found to be significant statistically. This is not different from that already documented $[19,20]$. 


\section{Conclusion}

Disease of the nose and paranasal sinuses are commonly seen in ENT practice and rhinosinusitis is the commonest entity encountered with inflammatory polyp as the commonest histopathologic finding. Squamous cell carcinoma was the commonest malignant lesion seen occurring more in males. Age distribution of the diseases was statistically significant.

There is need therefore to create public health awareness that it is not every nasal congestion and blockage that is "simple cold" so as to encourage early presentation thereby decrease rate of complications.

\section{Compliance with ethical standards}

\section{Acknowledgments}

We acknowledge the help of the outpatient staff of the ENT Surgery department and theatre staff as well for their help with the registers and records which were our source of data

\section{Disclosure of conflict of interest}

None declared.

\section{Statement of informed consent}

Owing to the fact that study was retrospective and data was from records and not directly from the patients.

\section{References}

[1] Adoga AA, Nuhu DM. The epidemiology and economic impact of rhinosinusitis in Jos, North- Central Nigeria. Journal of clinical Research Bioethic. 2011; 2: 11-16.

[2] Handi PS, Patil MN. Evaluation of nose and paranasal sinus disease, anatomical variations by computerized tomography. Int J Otorhinolaryngol Head Neck Surg. 2017; 3(4): 898-903.

[3] Lasis A0, Adeosun AA. Traditional open surgery for advanced benign nasal tumors in an era of endoscopy: review of 38 cases. African Journal of Health Science. 2007; 14(1): 1-2.

[4] Callus L, Bruaene NV, Bosteels C, Dejonckheere S, Zele TV, Holtappels G et al. Twelve -year follow up study after endoscopic sinus surgery in patients with chronic rhinosinusitis with nasal polyps. Clin Transl Allergy. 2019; 9: 30 .

[5] Khanna A, Sama A. Managing complications and revisions in sinus surgery. Current Otorhinolaryngology Reports. 2019; 7(1): 79-86.

[6] Adegbiji WA, Aremu SK, Akanbi GO, Omotayo JA. Clinicoepidemiological presentation of sinonasal mass in a Nigerian Tertiary Health Care Centre. Int J Biomed Sci. 2019; 15(3): 84-90.

[7] Bakari A, Afolabi O, Adoga AA, Kodiya A, Ahmad B. Clinico-pathological profile of sinonasal masses: an experience in National ear care. Center Kaduna, Nigeria.Research notes. 2010; 3: 186.

[8] Onotai LO, Mbalaso OC.Rhinologic surgeries in the university of Port Harcourt teaching Hospital :a 5years retrospective analysis. Gazette of medicine. 2014; 3(1): 241-245.

[9] Settpane GA. Epidemiology of nasal polyps. Allergy Asthma Proc. 1996; 17: 231-236.

[10] Wright J. History of laryngology and rhinology.1893; St Louis: Lea and Febriger. 1914; 57-59.

[11] Hedman J, Kaprio J, Poussa T, Nieminen MM. Prevalence of asthma, aspirin intolerance, nasal polyposis and chronic obstructive pulmonary disease in a population- based study. Int J Epidemiol. 1999; 28: 717-722.

[12] Laren PL, Tos M. Anatomic site of origin of nasal polyps: endoscopic nasal and paranasal sinus surgery as a screening method for nasal polyps in autopsy material. Rhinology. 1994; 33: 185-188.

[13] Alabi BS, Afolabi OA, Omokanye HK, Dunmade AO, Ayodele SO. Clinical presentation and outcome of sinonasal tumors in a Nigerian Tertiary Hospital-6-year-Review. Niger Med J. 2017; 58(3): 92-95. 
[14] Prakash M, Carlton JJ. Nasal rhinosporidiosis with an atypical presentation. Journal of pharmacy \& bioallied Sciences. 2015; 7(1): S72.

[15] Rizzo S, Giunta AAM, Pennacchi A. Sinonasal and rhinopharyngeal solitary fibrous tumor: a case report and review of literature. Acta Otorhinolaryngologica Italica. 2015; 35(6): 455.

[16] Fasunla AJ, Ogunkeyede SA. Factors contributing to por management outcome of sinonasal malignancies in South -west Nigeria. Ghana Med. 2013; 47: 10-15.

[17] Ogunleye AO, Ijaduola GT, Sandabe MB. Usual and unusual features of sinonasal cancer in Nigerians Africans: A prospective study of 27 patients. Ear Nose Throat J. 2008; 87: E13-17.

[18] Adegbiji WA, Olajide GT, Olatoke F, Oyebanji AO, Nwawolo CC. Sociodemographic profile and pattern of sinonsal injuries at the Ekiti State University Teaching Hospital Ado-Ekiti, South-West Nigeria. Nigerian Journal of family Practice. 2018; 9(3): 25-31.

[19] Ajiya A, Abdullahi H, Shuaibu IY. Clinicopathologic profile of sinonasal neoplasms in Kano, North Western Nigeria: A 10-year single institution experience. Annals of African Medicine. 2020; 19(3): 191-197.

[20] Lathi A, Syed MMA, Kalakoti P, Qutub D, Kishve SP. Clinicopathological profile of sinonasal masses: a study from a tertiary care hospital of India. Acta Otorhinolaryngol Ital. 2011; 31(6): 372-377. 